\title{
Marrow Fibrosis Associated with a Philadelphia Chromosome
}

\section{Peter C. Nowell, Jeffrey A. Kant, Janet B. Finan, Peter A. Cassileth, and Curtis A. Hanson}

\begin{abstract}
Three patients had marked marrow fibrosis and an apparent Philadelphia (Ph) chromosome. Hematologic, cytogenetic, and molecular studies demonstrated the heterogeneity of such cases, including the first example of clinically typical myelofibrosis (MF) associated with a bcr gene rearrangement characteristic of chronic myelogenous leukemia (CML).
\end{abstract}

\section{INTRODUCTION}

Many cases of Philadelphia chromosome-positive $\left(\mathrm{Ph}^{+}\right)$ chronic myelogenous leukemia (CML) have some increase in reticulin fibers in the bone marrow (BM), and some also have increased deposition of collagen, particularly late in the clinical course [1]. Rarely, however, does a patient

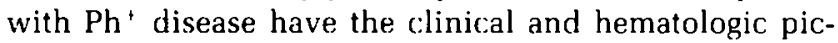
ture of typical myelofibrosis (MF), as currently defined [25]. We report two such patients and a third $\mathrm{Ph}^{\cdot}$ patient with sufficient marrow fibrosis to confuse the initial diagnosis.

\section{CASE REPORTS}

\section{Case 1 (P.W.)}

A 45-year old woman was noted to be anemic in February 1989 during hospitalization for a herniated disc. Subsequent studies showed a hemoglobin level of $8.8 \mathrm{~g} / \mathrm{dl}$, a white blood cell (WBC) count of $8.8 \times 10^{9} / \mathrm{L}$, and a platelet count of $987 \times 10^{9} / \mathrm{L}$. The peripheral blood (PB) smear showed nucleated red blood cells (RBC), teardrop forms, schistocytes, and a few immature leukocytes. Platelets were increased, with megakaryocyte fragments. A BM biopsy showed marked increase in fibrosis, megakaryocytic hyperplasia, and markedly increased reticulin. The leukocyte alkaline phosphatase (LAP) level was 6 (normal = 27-67). A clinical diagnosis of MF was made. Cytogenetic and molecular genetic studies were made of the BM at that time.

She was entered on an MF protocol involving treatment

From the Departments of Pathology and Laboratory Medicine (P. C. N., J. A. K. J. B. F.) and Medicine (P. A. C.), University of Pennsylvania School of Medicine, Philadelphia, Pennsylvania, and the Department of Pathology (C. A. H.), University of Michigan Medical School, Ann Arbor, Michigan.

Address reprint requests to: P. C. Nowell, M.D. Department of Pathology and Laboratory Medicine, University of Pennsylvania School of Medicine, Philadelphia, PA 19104-6082

Received July 1, 1991; accepted July 15, 1991. with interferon (IFN) daily, resulting in marked improvement in hemoglobin and platelet levels. In April 1990, she received a $B M$ transplant from a sibling and currently (July 1991) has no evidence of her primary disease.

\section{Case 2 (S.S.)}

A 61 -year-old man was first studied in London in December 1986 because he had dyspnea on exertion and ankle edema. He had a hemoglobin level of $8.4 \mathrm{~g} / \mathrm{dl}$, a WBC count of $16 \times 10^{9} / \mathrm{L}$, and a platelet count of $1,500 \times 10^{9} / \mathrm{L}$. The PB smear showed basophilia, anisocytosis, and teardrop forms. Bone marrow biopsy showed panmyelosis, islands of blasts, and increased reticulin fibers, considered to represent "agnogenic myeloid metaplasia with myelofibrosis." The LAP was not determined. During the next $2 \frac{1}{2}$ years, he was treated at several institutions in the United Kingdom and the United States, requiring increasingly fre$q$ lent transfusions. The clinical and hematologic diagnosis of MF was confirmed on at least two subsequent occasions by repeat $\mathrm{BM}$ examination, including one in September 1989, when cytogenetic and molecular genetic studies were also performed. The clinical course remained generally unchanged, with supportive therapy and without progression to acute leukemia, until the patient's death owing to cardiac complications in February 1991.

\section{Case 3 (J.F.)}

A 55-year-old woman was studied in December 1989 because of fatigue, weight loss, and lower-leg edema. Splenomegaly was noted. Her hemoglobin was $7.6 \mathrm{~g} / \mathrm{dl}$, and the WBC count was $93 \times 10^{9} / \mathrm{L}(28 \%$ segments, $14 \%$ bands, $4 \%$ lymphocytes, $1 \%$ monocytes, $7 \%$ eosinophils, $13 \%$ basophils, $9 \%$ atypical lymphocytes, $7 \%$ metamyelocytes, $14 \%$ myelocytes, $2 \%$ promyelocytes, and $1 \%$ blasts). The platelet count was $613 \times 10^{9} / \mathrm{L}$. The PB smear showed nucleated RBC, with occasional teardropping and large platelet forms. The LAP was 26. Bone marrow biopsy showed greatly increased numbers of megakaryocytes and areas of marked fibrosis alternating with other areas of marked hyperplasia, with nests of cells that appeared to be 
blasts. Chromosome studies were made of the BM in January 1990, and the patient was then treated with hydroxyurea, with normalization of her WBC and platelet counts. Since February 1990, she has been participating in a longterm protocol involving treatment with IFN, and her disease has been stable. Repeat chromosome studies were performed in May, August, and November 1990, with molecular studies also performed on the latter specimen.

\section{MATERIALS AND METHODS}

For chromosome studies, standard G-banded preparations were made from $\mathrm{BM}$ or $\mathrm{PB}$ specimens cultured for 24 hours without mitogen [6].

To determine the involvement of the bcr locus, DNA from cases 1 and 3 was hybridized with both a partial cDNA probe $|7|$ and a genomic probe (Oncogene Science) for the bcr major breakpoint cluster region [8]. For case 2 , RNA was extracted from glass slide smears of $B M$, and PCR amplification studies for bcr-abl chimeric mRNA were performed, as described previously [9]. Controls included a known positive CML specimen, which showed evidence of bcr-abl mRNA; appropriate negative controls; and analysis of the patient sample for c-abl mRNA, which demonstrated that intact mRNA had indeed been isolated from the glass slide specimen.

\section{RESULTS}

As indicated in Table 1 and Fig. 1, all BM cells from case 1 had the karyotype $46, X X, t(9 ; 22)(q 34 ; q 11)$,del(20)(q12). The molecular studies showed a single rearranged bcr allele with EcoRI, BamHI, and BgIII enzymes. The pattern suggested that the breakpoint was located in the F2 or F3 region of Shtalrid [10], toward the $3^{\prime}$ end of the major breakpoint region of typical CML.

In case 2 , although the cytogenetic abnormalities involved the same three chromosomes as in case 1. with an apparent Ph chromosome, there was not actually a t $(9: 22)$. As indicated in Table 1 and Fig. 2, the karyotype was interpreted as $46, X X, t(20 ; 22)(p 13 ; q 11)$,del(9)(q34). All metaphases examined were abnormal, and approximately one third were polyploid, with the same chromosome aberrations. The possibility of a "masked" bcr-abl translocation was considered, but the PCR amplification studies provided no evidence of bcr-abl chimeric mRNA.

In case 3 , the original chromosome study, performed at another institution, demonstrated a Ph chromosome, and our subsequent three studies of $\mathrm{BM}$ and PB, summarized in Table 1, confirmed the karyotype of the neoplastic cells as $46, X X, t(9 ; 22)(q 34 ; q 11)$. All metaphases were abnormal and, as with case 2 , a proportion were polyploid, consistent with the observed megakaryocytosis and thrombocytosis. As in case 1, molecular studies for bor involvement showed a single rearranged bcr allele with both the $\mathrm{BamHI}$ and BgIII enzymes. In this case, the pattern indicated that the breakpoint was located in the F1 region, toward the 5' end of the major breakpoint region.

\section{DISCUSSION}

These three cases illustrate a variety of ways in which severe marrow fibrosis may be associated with a Ph chro mosome. The first case represents the rare circumstance in which the karyotypic abnormalities in a patient with typical MF include the characteristic $t(9 ; 22)$ usually associated with CML. Only one such case is listed in the 1988 Mitelman catalogue [4], and a few others have been described in earlier articles $[2,3]$. None have been previously studied for bcr rearrangement. The fibrous proliferation in MF is not part of the preneoplastic or neoplastic clone, but is apparently stimulated by products of the abnormal hemic cells, particularly platelet-derived growth factor (PDGF) [5.11, 12]. This helps to explain the coexistence of megakaryocytosis and marrow fibrosis in this case, as well as in case 3 , although it is not known what genetic alteration, if any, in the neoplastic cells, other than the bcr-abl translocation contributes to this phenomenon. In case 1 , the del(20q) abnormality may have contributed to the specific phenotype. However, although this alteration does occur nonrandomly in MF, it has also been assocjated with a variety of other myeloproliferative and myelodysplastic; disorders $[4,5,13-16]$, as well as with some cases of $\mathrm{Ph}$. CML without significant MF $[17,18]$. There has been recent speculation that this $\operatorname{del}(20)(q 13)$ abnormality might specifically involve the hok gene (C: Willman, personal communication), which maps to this region and codes for a tyrosine kinase, but this has not been confirmed, and in this particular case no rearrangement of the hok gene was detected on standard Southern blots (K. Huebner, personal communication).

The second case was also considered typical MF when studied clinically and hematologically at a number of medical centers in the United States and the United King-

Table 1 Cytogenetic and molecular findings

\begin{tabular}{|c|c|c|c|c|c|}
\hline Patient & Date? & Specimen & $\begin{array}{l}\text { No. of } \\
\text { metaphases }\end{array}$ & Karyotype? & $\begin{array}{l}\text { ber-abl } \\
\text { Rearrangement }\end{array}$ \\
\hline 1 (P. W.) & $2 / 1989$ & Marrow & 25 & $46, X X, t(9: 22)(q ; 34: q 11), \operatorname{del}(20)(q 12)$ & Positive \\
\hline 2 (S. S.) & $9 / 1989$ & Marrow & $30^{4}$ & $46, X Y, 9(20 ; 22)(p 13: q 11), \operatorname{del}(9)(q 34)$ & Negative \\
\hline \multirow[t]{3}{*}{$3(\mathrm{~J} . \mathrm{F})}$. & $6: 1990$ & Marrow & $25^{\prime \prime}$ & $46, X X, t(9 ; 22)(q 34 ; q 11)$ & \\
\hline & $9 / 1990$ & Marrow & 12 & $46, X X, 1(9: 22)(434: 411)$ & \\
\hline & $12 / 1990$ & Blood & $25^{\prime \prime}$ & $46, X \times .1(9 ; 22)(q ; 34 ;(111)$ & Positive: \\
\hline
\end{tabular}

"Ten to $30 \%$ tetraploid. 


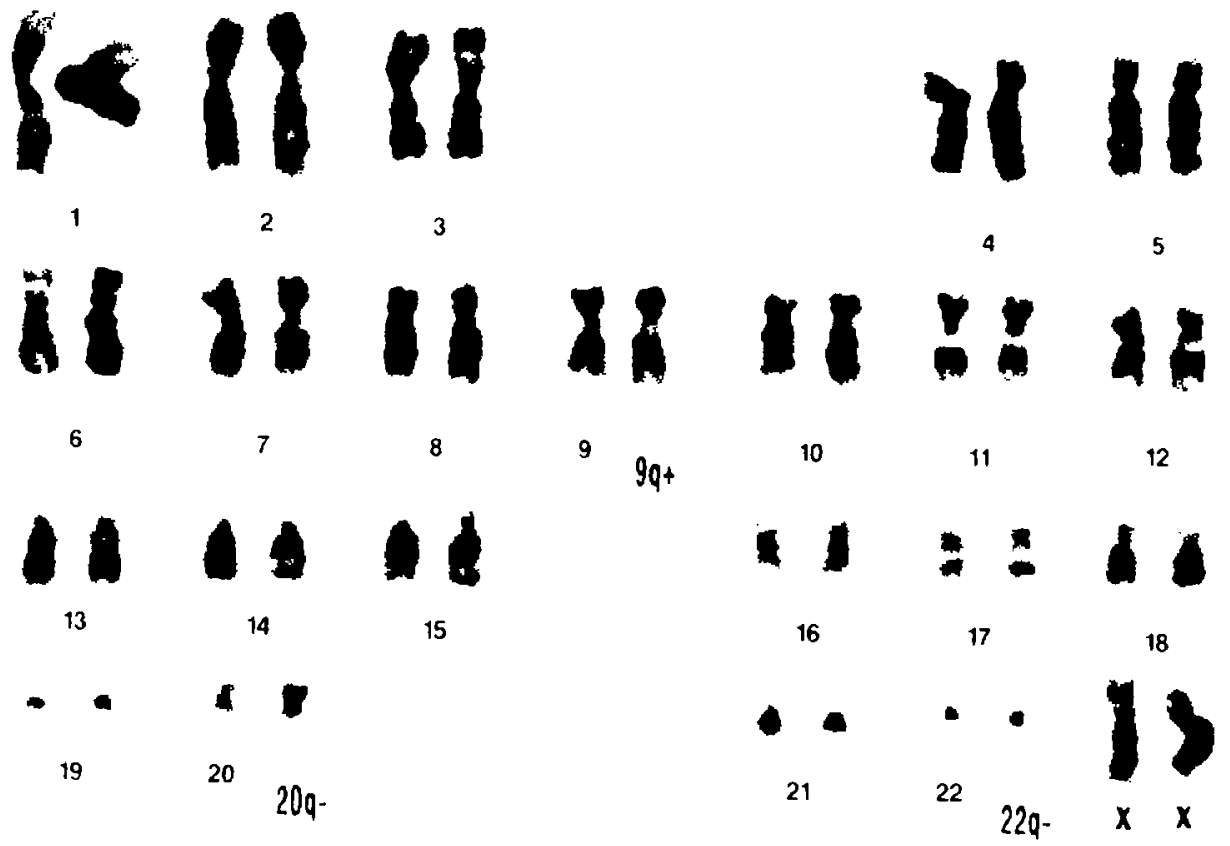

Figure 1 Representative karyotype from marrow of patient 1 (P.W.): 46,XX,t(9;22)(q34:q11),del(20)(q12).

dom. The karyotype also appeared initially to contain a Ph chromosome. However, both cytogenetic and molecular analysis indicated that there was not a bcr-abl translocation, but instead an unusual $t(20 ; 22)(\mathrm{p} 13 ; \mathrm{q} 11)$, as well as a small deletion from the terminal portion of the long arm of one chromosome 9 . The $t(20 ; 22)$ has not previously been described in myeloproliferative or myelodysplastic disorders, but there have been at least two reported cases of $\mathrm{Ph}^{+}$
CML with translocations involving the short arm of chromosome 20, although neither was confirmed at the molecular level as having a bcr rearrangement. In one instance, the translocation was described as $t(9 ; 20 ; 22)(q 34 ; p 11-$ $13 ; \mathrm{q} 11)[19]$, and in the other as simply $\mathrm{t}(20 ; 22)(\mathrm{p} 12 ; \mathrm{q} 11)$ [20]. Because of the overall rarity in hemic disorders of these rearrangements involving $20 \mathrm{p}$, speculating about their significance is difficult.

Figure 2 Representative karyotype from marrow of patient 2 (S.S.): 46.XY.t(20:22)(p13;q11),del(9)(q34).
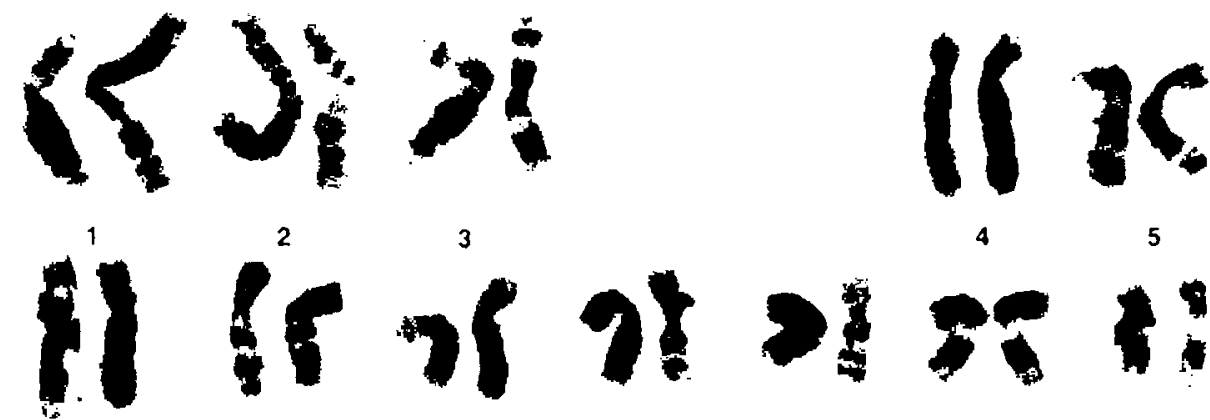

2

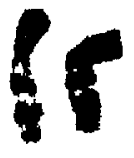

7
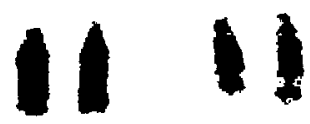

13

14
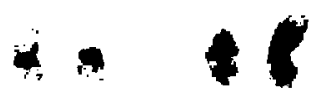

19

20

$20 p+$

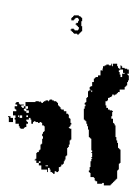

8

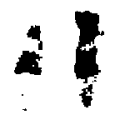

15

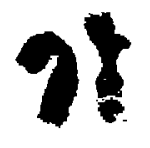

9

9q-

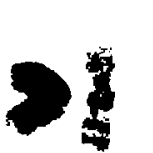

10

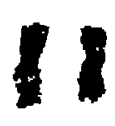

16

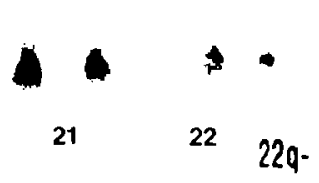

5

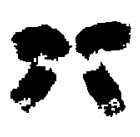

11
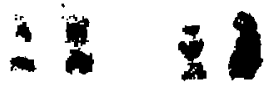

18

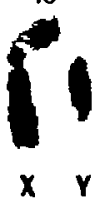


The third case exemplifies a somewhat more common entity in the spectrum of disorders that range from typical CML with minor degrees of marrow fibrosis and/or megakaryocytosis to $\mathrm{Ph}^{+}$cases initially appearing as typical essential thrombocythemia (ET) with marked increase in megakaryocytes and platelets and with some degree of marrow fibrosis $[21,22]$. This particular case was unusual in that the severity of the fibrosis complicated the original diagnosis, raising a question of whether the patient should be considered, and managed, as having MF or CML. These three cases indicate the need for careful evaluation, including appropriate cytogenetic and molecular studies, of all patients who initially have severe marrow fibrosis, as treatment options are considered.

This work was supported in part by Grant No. CA-42232 from the National Cancer Institute.

The authors thank Drs. S. Campbell. J. Cranick. M. Haut, and D. Wright for cooperation.

\section{REFERENCES}

1. Lorande-Metze I, Vassallo. J, Souza CA (1987): Histological and cytological heterogeneity of bone marrow in Philadelphia-positive chronic myelogenous leukaemia at diagnosis. $\mathrm{Br}$ I Haematol 67:45-49.

2. Clough V, Geary CG, Hashmi K, Davson J, Knowison 'T (1979): Myelofibrosis in chronic granulocytic leukaemia. $\mathrm{Br} J$ Haematol 42:515-526.

3. Georgii A. Vykoupil RF. Thiele J (1984): Chronic myeloproliferative disorders. Histopathology of bone marrow and clinical findings in chronic myeloproliferative disorders. In: Pathology of the Bone Marrow: K Lennart, K Hubner, eds. Gustav Fischer Verlag, Stuttgart.

4. Mitelman F (1988): Catalogue of Chromosome Aberrations in Cancer, 3rd ed. Alan R. Liss, New York.

5. Sandberg AA (1990): The Chromosomes in Human Cancer and Leukemia, 2nd ed. Flsevier, New York.

6. Nowell PC, Vonderheid EC, Besa F, Hoxie JA, Moreau L. Finan JB (1986): The most common chromosome change in 86 chronic B cell or T cell tumors: A $14 \mathrm{q} 32$ translocation. Cancer Genet Cytogenet 19:219-227.

7. Shtivelman E, Lifshitz, B, Gale RP, Canaani E (1985): Fused transcript of $a b l$ and $b c r$ genes in chronic: myelogenous leukaemia. Nature 315:550-554.

8. Groffen J. Stephenson JR, Heistercamp N. De Klein A, Bartram CR. Grosveld G (1984): Philadelphia chromosomal break- points are clustered within a limited region, bcr on chromosome 22. Cell 36:93-99.

9. Hanson CA, Holbrook EA, Sheldon S, Schnitzer B, Roth MS (1990): Detection of Philadelphia chromosome-positive cells from glass slide smears using the polymerase chain reaction. Am J Pathol 137:1-6.

10. Shtalrid M, Talpaz. M, Kurzrock R, Kantarjian H. Trujillo J, Gutterman J, Yoffe G, Blick M (1988): Analysis of breakpoints within the bor gene and their correlation with the clinical course of Philadelphia-positive chronic myelogenous leukemia. Blood 72:485-490.

11. Nowell PC. Finan IB (1978): Cytogenetics of acute and chronic: myelofibrosis. Virchows Arch [B| 29:45-50.

12. Buschle M, Janssen JWG, Drexler H, Lyons J, Anger B. Bartram C.R (1988): Evidence for pluripotent stem cell origin of idiopathic myelofibrosis: clonal analysis of a case charac: terized by a $\mathrm{N}$-ras gene mutation. Leukemia 2:658-660.

13. Yunis IJ. Rudell RF. Oken MM. Arnesen MA. Mayer MG, Lo)bell M. (1986): Refined chromosome analysis as an independent prognostic indicator in de novo myelodysplastic syndromes. Blood 67:1721-17:30.

14. Rege-Cambrin G, Mecucci C. Tricot G, Michaux JI, Louwagie $A$, Van Hove $W$, Francart $H$, Van Den Berghe $H$ (1987): A chromosomal profile of polycythemia vera. Cancer Genet $\mathrm{Cy}$ togenet 25:233-245.

15. Sessarego M, Defferrari R. Dejana $\Lambda M$, Rebuttato $\Lambda$ M. Fugazza G. Salvidio E. Ajmar F (1989): Cytogenetic analysis in essential thrombocythemia at diagnosis and at transformation. Cancer Cenet Cyrtogenet 43:57-65.

16. Nowell PC. Besa HC. (1989): Prognostic: significance of single? chromosome abnormalities in preleukemic states. Cancer Crenet Cytogenet 42:1-7.

17. Testa JR, Kinnealey A, Kowley JD, Golde DW, Potter I) (1978): Deletion of the long arm of chromosome 20 [del(20)(q11)] in myeloid disorders. Blood 52:868-877.

18. Hild F. Fonatsch C (1990): Cytogenetic peculiarities in chronic myelogenous leukemia. Cancer Genet Cytogenet 47:197-217.

19. Casalone R, Bernasconi P. Pasquali F (1983): Lnvolvement of chromosome no. 20 in a complex $\mathrm{Ph}^{\prime}$ translocation. Cancer Genet Cytogenet 8:181-182.

20. I.ai JL, Jonet JR, Bauters F, Deminatti M (1982): Anomalie chromosomique nouvelle par translocation $t(20: 22)$ au cours d'une leucérnie myéloïde chronique. Nouv Presse Med $11: 3270$.

21. Rajendra BR, Lee ML, Nissenblatt MJ, Gartenberg G. Rose DV, Sciurra LJ (1981): The occurrence of the Philadelphia chromosome in essential thrombocytosis. Hum Genet 56:287-291.

22. Michiels JI. Prins ME, Hagemeijer A, Brederoo P, van der Meulen J, van Vliet HHDM. Abels J (1987): Philadelphia chromosome-positive thrombocythemia and megakaryoblast leukemia. Am J Clin Pathol 88:645-652. 